\title{
Review Article \\ Dendritic Cells in the Gut: Interaction with Intestinal Helminths
}

\author{
Fela Mendlovic ${ }^{1,2}$ and Ana Flisser ${ }^{1}$ \\ ${ }^{1}$ Departamento de Microbiología y Parasitología, Facultad de Medicina, Universidad Nacional Autónoma de México (UNAM), \\ Avenue Universidad 3000, Colonia Copilco Universidad, México DF 04510, Mexico \\ ${ }^{2}$ Escuela de Ciencias de la Salud, Universidad Anáhuac México Norte, Avenue Universidad Anáhuac 46, Huixquilucan, \\ 52786 Estado de México, Mexico
}

Correspondence should be addressed to Ana Flisser, flisser@servidor.unam.mx

Received 22 August 2009; Revised 30 November 2009; Accepted 18 December 2009

Academic Editor: Luis I. Terrazas

Copyright (C) 2010 F. Mendlovic and A. Flisser. This is an open access article distributed under the Creative Commons Attribution License, which permits unrestricted use, distribution, and reproduction in any medium, provided the original work is properly cited.

\begin{abstract}
The mucosal environment in mammals is highly tolerogenic; however, after exposure to pathogens or danger signals, it is able to shift towards an inflammatory response. Dendritic cells (DCs) orchestrate immune responses and are highly responsible, through the secretion of cytokines and expression of surface markers, for the outcome of such immune response. In particular, the DC subsets found in the intestine have specialized functions and interact with different immune as well as nonimmune cells. Intestinal helminths primarily induce Th2 responses where DCs have an important yet not completely understood role. In addition, this cross-talk results in the induction of regulatory $\mathrm{T}$ cells ( $\mathrm{T}$ regs) as a result of the homeostatic mucosal environment. This review highlights the importance of studying the particular relation "helminth-DC-milieu" in view of the significance that each of these factors plays. Elucidating the mechanisms that trigger Th2 responses may provide the understanding of how we might modulate inflammatory processes.
\end{abstract}

\section{Introduction}

Dendritic cells (DCs) were first identified around 140 years ago. Nevertheless their role in immunology was discovered more than 100 years later, in 1973; and, since then, ongoing research on their localization, phenotypic characterization, and functions is still taking place [1]. DCs in the intestine show two major paradoxical roles. On one hand they are responsible for the generation of immunological tolerance in absence of infection or danger signals, albeit the presence of a myriad of intestinal commensal microorganisms and alimentary antigens; and, on the other hand, they must be able to react and induce specific immune responses against pathogens $[2,3]$. Intestinal helminths constitute a cause of high morbidity and chronic infections in humans [4]. Chronicity is probably associated with immunomodulation of the intestinal immune response. In this context, current evidence indicates that helminth products are capable of inhibiting in vitro generated DCs [5-7]. While there is a vast amount of studies on DCs and gut bacteria $[8,9]$, only few publications describe the interaction of intestinal parasites and these cells. Since DCs from intestine have inherent characteristics regarding their ability to induce Th2 responses $[2,3,10]$, the study of this particular interaction is of fundamental importance. The cross-talk between intestinal helminths or their excretion/secretion $(\mathrm{E} / \mathrm{S})$ products and the different DC subsets present in the gut, which result in the induction of Th2 responses and regulatory $\mathrm{T}$ cells ( $\mathrm{T}$ regs) in that milieu, is reviewed.

\section{Intestinal Immunity}

The first line of defense against pathogens and exogenous antigens present in the gastrointestinal (GI) tract includes the physical barrier provided by epithelial cells (enterocytes), the tight junctions formed between them, the ciliary movements, the mucus secretion by goblet cells on the apical portion of the mucosa, microfold (M) cells, the cytotoxic activity of natural killer cells, as well as the production of antibacterial peptides by Paneth cells that include defensins, lysozyme, and secretory phospholipase A2. The adaptive immune system in the GI tract includes the GI-associated lymphoid tissue 
(GALT), comprising Peyer's patches (PPs), isolated lymphoid follicles (ILFs), and diffuse lymphoid cells present along the lamina propria (LP) in the small intestine. In the large intestine, caecal and rectal patches are similar to individual follicles of the PPs. Cryptopatches (CPs), aggregates of lymphocytes and DCs should also be considered part of the immune system, since they are present throughout both the small and large intestines, in the LP between the crypts [11]. CPs have been shown to develop into ILFs recruiting B cells, in response to Gram-negative commensal bacteria through recognition of NOD-1 (nucleotide-binding oligomerization containing domain 1) and toll-like receptors resulting in generation and maturation of B cells, respectively. In addition, alterations in gut microflora composition occur in mice that lack NOD-1 showing reciprocal regulation of the intestinal microflora and ILFs which in turn affects intestinal homeostasis [12]. These findings can significantly contribute to development of novel treatments for pathologies involving intestinal inflammation through the modulating capacity of commensal by-products. The gut epithelium, lamina propria, and intraepithelial lymphocytes (IELs) represent the lymphoid effector sites, while mesenteric lymph nodes (MLNs), PPs, and ILFs are considered inductive sites where immune responses are initiated. Immune cells migrate from LP and PPs via efferent lymphatics to MLN and finally reach effector sites, traveling through the thoracic duct and blood circulation.

PPs consist of collections of closely associated lymphoid follicles. The epithelium that covers these aggregates, termed follicle-associated epithelium, is characterized by the presence of specialized cells, $M$ cells that lack cilia and take up antigens releasing them at the basal surface, where associated antigen presenting cells start their processing and latter presentation to lymphocytes. Just beneath the follicle-associated epithelium, PPs consist of a dome region, populated by $\mathrm{T}$ and $\mathrm{B}$ cells, macrophages, and different subsets of DCs. B cells that switch to IgA producing plasma cells that prevail in the germinal centers and TCR $\alpha \beta \mathrm{CD}^{+} \mathrm{T}$ cells, which represent the predominant phenotype, are found in interfollicular regions accompanied by interstitial DCs. TCR $\gamma \delta$ and CD8+ T cells are also present. PPs contain both naïve and memory $\mathrm{T}$ and $\mathrm{B}$ cells whereas in the LP only memory cells and fully differentiated plasma cells are present. The spatial cell organization of these lymphoid organs makes them suitable to deal with both harmless and hazardous stimuli from incoming antigens. DCs represent one of the cell types in charge of differentiating between these two completely opposite phenomena and regulating the outcome of the immune response $[2,13]$.

Afferent lymphatics drain the epithelium and LP from both the small and large intestines to MLNs which are organized along the mesenteric side of the intestine and drain succeeding sections of the gut. Like other lymph nodes, MLN consist of B cells that are organized as lymphoid follicles in the cortex, while T cells and DCs shape the paracortical areas. Efferent lymphatic vessels leave the lymph node from the medulla and drain to the thoracic duct and finally to the systemic circulation. Stromal cells in MLN are important in imprinting antigen primed $\mathrm{T}$ cells with the capacity to express $\alpha 4 \beta 7$ integrin and chemokine receptor 9 (CCR9) that are essential molecules in gut homing. Expression of these two molecules is dependent on retinoic acid and stromal cells from MLN, but not from peripheral $\operatorname{LN}[14,15]$. In addition, MLNs have been shown to be important in the regulation of IgA responses since removal of these organized lymphoid structures results in an enhanced IgA response to orally administered antigens [16]. Thus, MLNs contribute to gut homeostasis and effector mechanisms by providing regulatory environmental factors.

Besides the organized tissues, cells in diffuse compartments, that is, cells in LP and IEL, are important players in mucosal immunity. Memory/effector cells home to the LP and plasma cell differentiation is accomplished in this compartment. LP stromal cells support IgA secreting plasma cells generation from $\mathrm{B}_{2} 20^{+} \mathrm{IgM}^{+}$lymphocytes [17]. The majority of IELs are T lymphocytes expressing CD3 and the T cell receptor, either $\alpha \beta$ or $\gamma \delta$. Most IELs in the small intestine are $\mathrm{CD}^{+}$and are able to express regulatory properties and secrete IL- 10 and TGF- $\beta$. In addition, IELs are able to secrete cytokines and chemokines as well as cytotoxic molecules during inflammatory conditions contributing to the dual function of mucosal immunity in tolerance and defense [18].

\section{DC Subsets}

Several hematopoietic DC subsets have been described in mice and are often classified on the basis of the surface receptors they express, developmental origin, anatomical localization, migratory and functional properties, and their maturation state. Such heterogeneity makes a single classification of DCs rather difficult; nonetheless, some common phenotypical and functional characteristics are used to define DCs, besides their prominent dendritic appearance, both in situ and in vitro: (i) CD11c expression, (ii) endocytic ability, (iii) high expression of MHC-II molecules, and (iv) strong capacity to activate naïve T cells [19]. Hematopoietic DCs are subdivided in two main subsets: plasmacytoid DCs (pDCs) and conventional DCs (cDCs) [20]. A distinctive feature of pDCs is their rapid and very high production of type I IFN when properly stimulated (virus, DNA, etc.). When activated, expression of MHC-II and costimulatory molecules is upregulated. Compared to conventional DCs, pDCs are less efficient as antigen presenting cells, although they are able to stimulate naïve $\mathrm{T}$ cells in addition to cells from the innate immune response (e.g., natural killer cells). pDCs express intermediate amounts of $\mathrm{CD} 11 \mathrm{c}^{+}$and are $\mathrm{B} 220^{+}$. These DCs mature in the bone marrow, are found in all lymphoid organs and blood, and are capable of recirculating [21]. On the other hand, cDCs are also bone marrow derived but emerge with an immature phenotype characterized by low expression of MHC-II and costimulatory molecules and are present in different organs and lymphoid tissues. cDCs can be further subdivided in migratory and resident DCs. Migratory DCs include Langerhans cells in epidermis and interstitial DCs in all organs and the gut, mainly in their immature state. Upon encountering antigen they drain to regional lymph nodes acquiring a mature phenotype, and in the case of the gut, they travel into T cell areas of MLN. The second subset 
of cDCs is the resident DCs that are the only type present in spleen and thymus and account for $\sim 50 \%$ of the DC population present in lymphoid organs probably emerging from blood precursors and differentiating in situ $[3,20,21]$. Until they encounter pathogens, resident DCs express an immature phenotype. These cells apparently do not exit lymphoid tissues and can be further subdivided depending on surface marker expression. All these $\mathrm{cDC}$ subsets express both CD11c and MHCII $[2,20]$.

As mentioned above, both pDCs and cDCs are able to modify their phenotype and functional capabilities in response to external stimuli resulting in a further classification of DCs in immature (naïve) and mature DCs. These two different conformations result in the differential expression of surface markers. Immature cells express very low levels of costimulatory molecules such as CD80, CD86, and CD40. In this state, DCs are highly endocytic and express C-type lectin receptors such as Langerin/CD207 and DEC 205, involved in antigen capture and internalization. In addition, innate receptors involved in antigen recognition such as Toll-like receptors (TLRs) that recognize pathogenassociated molecular patterns (PAMPs) are also present and are differentially expressed in the various subsets. In their mature state, DCs upregulate costimulatory surface antigens which are important for $\mathrm{T}$ cells interaction and activation $[22,23]$.

\section{Intestinal DCs}

Along the small and large intestines, DCs are present in different locations. Both $\mathrm{pDCs}$ and $\mathrm{cDCs}$ are present in PPs, MLN, as well as in the small intestinal and colonic LP and ILFs. Various DC subpopulations expressing different surface markers and showing diverse functional properties can be identified (Table 1). Surface antigen expression can be associated with specific locations within the lymphoid tissue and importantly with functional characteristics. For example, in PPs, DCs present underneath the follicleassociated epithelium are mainly immature cells expressing low MHC-I and -II and costimulatory molecules and are highly macropinocytic and phagocytic in order to sample the environment and process antigens that have passed through $M$ cells. In addition, these immature DCs express Tolllike, C-type lectin, and scavenger receptors which recognize PAMPs that, in the presence of microbial products and danger signals released by damaged tissue, are able to activate and induce their maturation. Mature DCs expressing high levels of MHC-II, CD80, CD86, and CD40 lose their endocytic ability and migrate from the subepithelial dome to $\mathrm{T}$ cell areas within the PPs or to the regional lymph nodes, where they can efficiently present antigen and activate $\mathrm{CD} 4^{+}$ $\mathrm{T}$ cells $[2,3]$.

Several examples of the unique functional properties and specific location of particular DC subsets can be cited. For instance, $\mathrm{CD} 8 \alpha^{+}$DCs are mainly found in the interfollicular region and preferentially secrete IL- 12 , while $\mathrm{CD} 11 \mathrm{~b}^{+} \mathrm{DCs}$ produce IL-10 upon stimulation and are localized mainly in the subepithelial dome of the PPs. Moreover, CD $11 b^{+}$ DCs induce T cells to secrete IL-4 and IL-10, and thus, are important in regulating immunity as well as facilitating IgAmediated humoral responses $[10,24]$. Additionally, CD11b ${ }^{+}$ DCs in PPs and MLN internalize secretory IgA. Neither $\mathrm{CD} 8 \alpha^{+}$nor DCs isolated from peripheral lymph nodes or spleen show this particular feature [25].

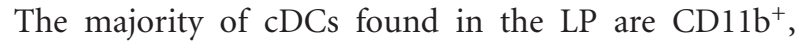
although small numbers of $\mathrm{CD} 8 \alpha^{+}$and double-negative cells $\left(\mathrm{CD} 8 \alpha^{-} \mathrm{CD}_{11 b^{-}}\right)$are present. Although $\mathrm{CD} 11 \mathrm{~b}^{+}$cells are able to upregulate costimulatory molecules and prime specific $\mathrm{T}$ cells, when they are adoptively transferred into recipient mice, they induce a lower response and express mRNA for IL-10 and IFN- $\beta$. It is important to clarify that LP DCs were isolated from small intestine devoid of PPs but containing ILFs; thus, these DCs do not represent true LP DCs [26]. In a different study, a CD11c ${ }^{+}$CD $11 b^{+}$DC subset that produces retinoic acid and is able to induce differentiation of Th17 cells and IgA producing plasma cells in the LP, upon activation of TLR5, was identified $[2,27]$. DCs isolated from LP could be contaminated with DCs present in ILFs; thus, immunohistochemical analysis should be performed to confirm which subsets are present in these two diffuse compartments. Interestingly, a CD103 expressing DC subset which constitutes $\sim 25 \%$ of the total LP DC populations constitutively expresses IL-10 and favors the maintenance of tolerance by inducing, through TGF$\beta$ and retinoic acid dependent mechanisms, the generation of FoxP3 ${ }^{+} \mathrm{T}$ regs in the intestine. These "regulatory DCs" are able to migrate to MLN in a CCR7 dependent manner [28-31]. Retinoic acid produced by $\mathrm{CD}_{103^{+}} \mathrm{DCs}$ imprints primed $\mathrm{T}$ cells and IgA expressing plasma cells to express gut homing receptors such as the integrin $\alpha 4 \beta 7$ and CCR 9 [32]. Accordingly, this DC subset expresses retinal dehydrogenase 2 (RALDH2), a key enzyme involved in the formation of retinoic acid from retinaldehyde [27]. In addition, some LP DCs are able to form tight-junction-like structures with enterocytes and project their dendrites to sample antigens in the intestinal lumen, both in normal conditions and during infection; hence, their name is "periscoping DCs" [33]. As cDCs in mucosal sites, pDCs in the GALT are able to induce differentiation of $\mathrm{T}$ reg cells and upon $\mathrm{CpG}$-induced maturation retain their regulatory capacity, suggesting the necessity of a strict regulatory environment in the gut [34].

Recently, a different population of DCs arranged as a planar network has been identified after a sheet separation technique that results in two layers: one facing the lumen and the other one the serosa. These DCs were localized in the muscularis layer close to the serosa and have surface antigens characteristic of an immature phenotype. Upon systemic or oral stimulation with LPS or bacteria, they are able to acquire a mature phenotype even though they are not close to the intestinal lumen. In addition, a higher frequency of these muscularis DCs was detected in the large intestine, where the concentration of commensal bacteria is higher, suggesting a possible association with microbial external stimuli and a possible immunoregulatory role [23]. Concerning the large intestine, DCs in the colon are very similar to the subpopulations present in MLN and reside mainly in the subepithelial region and in the isolated lymphoid follicles. These DCs express IL-10 in a constitutive manner, again 
TABLE 1: Intestinal DC subsets.

\begin{tabular}{|c|c|c|c|}
\hline DC subset & Organ & Functional characteristics & References \\
\hline $\begin{array}{l}* \mathrm{CD}_{11 \mathrm{~b}^{+} \mathrm{DCs}(1)} \\
{ }^{* *} \mathrm{CD} 8 \alpha^{+} \mathrm{DCs}(2) \\
* * * \operatorname{DN} \text { DCs }(3)\end{array}$ & Peyer's patches & $\begin{array}{l}\text { (1) During infection recruited to FAE from } \\
\text { subepithelial dome. (2) Produce IL-10. ( } 3 \text { ) Produce } \\
\text { IL-12 and drive IFN } \gamma \text { by T cells. }\end{array}$ & {$[2,3,19]$} \\
\hline $\begin{array}{l}* \mathrm{CD} 11 \mathrm{~b}^{+} \mathrm{DCs} \\
* * \mathrm{CD} 8 \alpha^{+} \mathrm{DCs} \\
* * * \mathrm{DN} \mathrm{DCs} \\
\mathrm{CD} 8 \alpha^{\text {int }} \mathrm{CD} 103^{+}\end{array}$ & Mesenteric lymph nodes & $\begin{array}{l}\mathrm{CD} 11 \mathrm{~b}^{+} \text {cells show higher capacity to secrete IL- } 10 \text { and } \\
\text { prime Th2 cells. CD } 103^{+} \text {DC migrate from LP in a } \\
\text { CCR7 dependent manner. }\end{array}$ & {$[3,28,35]$} \\
\hline $\begin{array}{l}\mathrm{CD} 11 b^{+} \\
\mathrm{CD} 8 \alpha^{\text {int }} \mathrm{CD} 103^{+}\end{array}$ & Lamina propria & $\begin{array}{l}\text { Constitutive expression of IL-10 and IFN- } \beta \text {. Extend } \\
\text { their dendrites to sample bacteria through epithelial } \\
\text { cell tight junctions. }\end{array}$ & {$[26]$} \\
\hline 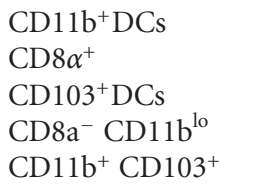 & Colon & $\begin{array}{l}\text { Constitutive expression of IL-10. Maintenance of T cell } \\
\text { homeostasis. Concentrated in isolated lymphoid } \\
\text { follicles (ILFs) few in lamina propria. }\end{array}$ & {$[2]$} \\
\hline $\begin{array}{l}\mathrm{MHCII}^{+} \mathrm{CD} 11 \mathrm{c}^{\mathrm{mid}} \\
\text { Dec } 205+, \text { Dec } 207 \\
\text { CD14, CD } 16 / 32\end{array}$ & Muscularis layer & $\begin{array}{l}\text { Not known. Possible correlation with increasing } \\
\text { number of commensal bacteria. }\end{array}$ & {$[23]$} \\
\hline  & $\begin{array}{l}\text { Lymphatic vessels } \\
\text { draining the intestine }\end{array}$ & $\begin{array}{l}\text { Transport of apoptotic bodies from intestinal epithelial } \\
\text { cells to regional lymph nodes. }\end{array}$ & {$[36]$} \\
\hline $\begin{array}{l}\mathrm{CD}_{11 c^{\mathrm{mid}}} \mathrm{B} 220^{+} \\
\text {(plasmacytoid } \\
\text { DCs) }\end{array}$ & $\begin{array}{l}\text { Peyer's patches, } \\
\text { Mesenteric Lymph } \\
\text { nodes, and Lamina } \\
\text { Propria (small intestine } \\
\text { and colon) }\end{array}$ & $\begin{array}{l}\text { PPs: production of type I IFN regulated by IL- } 10 \text {, } \\
\text { TGF- } \beta \text {, and prostaglandin } \mathrm{E}_{2} \text {. MLN: induction of T } \\
\text { regs. }\end{array}$ & {$[34,37]$} \\
\hline
\end{tabular}

suggesting a role in peripheral tolerance mechanisms [2]. Thus, DC subsets with immunomodulatory properties are well represented along the GI tract.

\section{Intestinal DCs and Infection}

Helminth infections affect more than three billion people worldwide, mostly in underdeveloped countries. The study of the immune response against geohelminths has revealed the importance of these parasites not only in the ability to induce Th2 responses, but also in the modulatory role of the parasite or its products on the immune system of the host. The protective host's immune response induced by helminths is mediated by Th2 cells involving IL-4, IL-5, IL10 , and IL-13 secretion, IgE, IgG1 production, and activation of effector cells such as mast cells, eosinophils, and basophils $[5,38,39]$. In addition, some helminths are able to persist in their hosts for many years by creating an antiinflammatory environment favorable to their survival and maintenance. DC modulation represents a potential mechanism by which helminths may exert their effects on the immune system.

In spite of increasing numbers of studies involving helminth products and DCs generated in vitro, few studies cope with the interaction of these parasites in the intestinal milieu (see below). The significance of studying these interactions is highlighted by the fact that there is rising research aimed on the use of helminth infections or their products as therapy for autoimmune, allergic, or inflammatory diseases [6]. In particular, intestinal DC subsets have unique characteristics and the effects helminths may exert upon them probably depend on several parameters, which include (i) the DC subset, (ii) the helminth species, (iii) the excretory/secretory (E/S) products, and (iv) the regulatory environment in the gut. These interactions will result in the different immunomodulatory mechanisms, such as downregulation of costimulatory or antigen-presenting molecules, IL-10 and TGF- $\beta$ secretion, and/or generation of $\mathrm{T}$ regs, depending on the biological players involved (Table 2).

The role of DCs and the phenotype induced during infection is essential in order to get insights of the cellular and molecular interactions in vivo, which include intestinal DC subsets within the appropriate environment, as well as the timing of production of E/S molecules by the established parasites. In mouse infections with Trichuris muris, an animal model for the human geohelminth, T. trichiura, the adult worms reside in the caecum and colon. IL-4 and IL-13 promote protection against the murine nematode in 
TABLE 2: Effect of intestinal helminth infections or their products on DC function.

\begin{tabular}{|c|c|c|c|c|}
\hline \multicolumn{2}{|c|}{ Intestinal helminth product } & \multirow{2}{*}{$\begin{array}{l}\text { DC subset } \\
\text { CD11c MLN DCs }\end{array}$} & \multirow{2}{*}{$\begin{array}{l}\text { DC response } \\
\text { Downregulation of CD 40, CD 80, CD86, } \\
\text { and MHCII induced by immunization. } \\
\text { Production of IL-10. }\end{array}$} & \multirow{2}{*}{$\begin{array}{c}\text { References } \\
{[40]}\end{array}$} \\
\hline Ascaris suum & $\begin{array}{l}\text { High molecular weight } \\
\text { components of adult } \\
\text { worms }\end{array}$ & & & \\
\hline \multirow[t]{2}{*}{$\begin{array}{l}\text { Heligmosomoides } \\
\text { polygyrus }\end{array}$} & Infection & $\begin{array}{l}\text { CD } 11 c^{+} \text {Spleen and } \\
\text { MLN DCs }\end{array}$ & $\begin{array}{l}\text { Activation with upregulation of CD } 80 \\
\text { and CD86. Production of IL- } 10 . \\
\text { Inhibition of protective response against } \\
\text { bacteria and exacerbated colonic } \\
\text { inflammation (pasive transfer of } \\
\text { Hp-DCs). }\end{array}$ & {$[41,42]$} \\
\hline & $\mathrm{E} / \mathrm{S}$ products & Bone marrow DCs & $\begin{array}{l}\text { Inhibition of cytokine production. } \\
\text { Inhibition of upregulation of CD40, } \\
\text { CD86, and MHCII by TLR engagement. } \\
\text { Induction of IL-10 producing T cells } \\
\text { (regulatory T cells). }\end{array}$ & {$[43]$} \\
\hline Necator americanus & E/S products & $\begin{array}{l}\text { Human } \\
\text { monocyte-derived DC }\end{array}$ & $\begin{array}{l}\text { Downregulation of CD86, CD1a, } \\
\text { HLA-ABC, and HLA-DR resulting in a } \\
\text { diminished capacity to induce T cell } \\
\text { proliferation. }\end{array}$ & {$[44]$} \\
\hline \multirow[t]{2}{*}{$\begin{array}{l}\text { Nippostrongylus } \\
\text { brasiliensis }\end{array}$} & E/S products & Bone marrow DCs & $\begin{array}{l}\text { Upregulation of CD } 86 \text { and Ox40L. No } \\
\text { effect on CD } 80 \text { and MHCI. Production of } \\
\text { IL-6, IL-10, and IL-12 p40. Inhibition of } \\
\text { LPS-induced IL-12 p70. }\end{array}$ & {$[45]$} \\
\hline & Infection & $\begin{array}{l}\mathrm{CD} 11 \mathrm{c}^{+} \mathrm{CD} 8 \alpha^{\mathrm{int}} \\
\mathrm{CD}_{103^{+}}\end{array}$ & $\begin{array}{l}\text { Reduction of this subpopulation during } \\
\text { infection. Reduction of CD } 86 \text { and Dec } \\
205 \text {. Reduced production of } 11-12 \text { and } \\
\text { increase in IL-6, TNF } \alpha \text {, and IL-10. In } H \text {. } \\
\text { polygyrus infection reduction of this DC } \\
\text { subset is more pronounced. }\end{array}$ & {$[46]$} \\
\hline \multirow[t]{3}{*}{ Trichuris muris } & Infection (E-J isolate) & $\mathrm{CD}_{11 \mathrm{c}^{+} \mathrm{MLN} \text { DCs }}$ & $\begin{array}{l}\text { Expansion of DCs correlates with worm } \\
\text { expulsion. Production of IL-4, IL-13, and } \\
\text { IL-10. }\end{array}$ & {$[47-49]$} \\
\hline & $\begin{array}{l}\text { E/S products }(\mathrm{S}, \mathrm{J}, \mathrm{E} \\
\text { isolates) }\end{array}$ & Bone marrow DCs & $\begin{array}{l}\text { S isolate induces higher levels of IL- } 6 \text { and } \\
\text { IL-10. Upregulation of CD } 40 \text { by all three } \\
\text { isolates. }\end{array}$ & {$[50]$} \\
\hline & Infection & CD11c ${ }^{+}$MLN DCs & $\begin{array}{l}\text { Thymic Stromal Lymphopoietin (TSLP) } \\
\text { produced by intestinal epithelial cells } \\
\text { (IECs) interacts with DCs inhibiting } \\
\text { LPS-induced IL12/23p } 40 \text { and increasing } \\
\text { IL-13 production. }\end{array}$ & {$[51,52]$} \\
\hline
\end{tabular}

contrast to Th1 cytokines such as IFN $\gamma$, IL-12, and IL-18 that help maintain a chronic infection depending on the mouse strain $[53,54]$. Resistance to infection has been associated with mobilization of colonic DCs to the epithelium since there is an increased number of DCs in resistant mice that developed a mature phenotype, compared to susceptible strains [55]. Accordingly, in a different study, the kinetics of DC numbers after $T$. muris infection revealed a correlation between increased numbers of CD11c $\mathrm{c}^{+} \mathrm{B} 220^{-} \mathrm{DC}$ in MLN and worm expulsion from the gut with the concomitant production of IL-4, IL-13, and IL-10 [47, 48]. IL-10 has been shown to be essential for the expulsion of T. muris from the gut, since IL-10 deficient mice fail to expel worms, resulting in a chronic infection [56]. CD11c DCs from PPs and MLN were shown to be responsible for the production of this cytokine although particular DC subsets were not identified [49]. In contrast, in a different study, IL-10 and IL6 production by bone marrow-derived DCs after activation with $\mathrm{E} / \mathrm{S}$ was correlated to the capacity of a particular isolate of T. muris to survive in its host [50]. Production of IL10 by DCs is also observed in MLNs of mice infected with the intestinal helminth $H$. polygyrus that induces a chronic infection in most inbred strains of mice [41]. Therefore, IL-10 production by DCs can induce worm expulsion or survival and this different outcome might be dependent on presence of other cytokines that might influence the Th1/Th2 balance. A very recent study analyzed the DC populations present in MLN during the absence or presence of infections with both Nippostrongylus brasiliensis (shortlived infection) and Heligmosomoides polygyrus (chronic infection). N. brasiliensis infection induces a reduction on $\mathrm{CD} 8 \alpha^{\text {int }} \mathrm{CD} 11 \mathrm{~b}^{-}$subset and decrease in CD40 and 
CD86 expression. The decline of this DC subset is more pronounced during $H$. polygyrus infection and could result from a lack of migration of this subset from LP. This subset represents the subpopulation that expresses the highest levels of CD103 and CD205. Concomitantly, cytokine production is altered; IL-12 production in response to LPS was reduced whereas IL-6, TNF $\alpha$, and IL-10 secretion was upregulated [46].

\section{DC Activation versus the "Default Hypothesis"}

Generation of Th1 responses through activation of DCs by viral or bacterial products is much better understood than Th2 induction. It is known that binding of those products to TLRs through activation of MyD88 initiates signaling cascades that result in enhanced expression of MHCII (signal 1) and costimulatory molecules such as CD80, CD86 and CD40 (signal 2) with concomitant production of IL-12 (signal 3). In turn, for Th2 responses signals 2 and 3 have not yet been identified. Indeed lack of costimulatory molecules, upregulation, and IL-12 induction have led to propose a "default hypothesis" [57]. E/S products of helminths are able to affect DC maturation in different ways, either through their activation (upregulation of MHC-II and costimulatory molecules) or through the inhibition of their maturation ("default response"). This response is characterized by a diminished gene expression and no upregulation of classical costimulatory molecules, both types of responses (activation and inhibition of DC) results in a type 2 phenotype $[39,58]$. For example, adult worm components from Ascaris suum have been studied for their ability to suppress the immune response. DC upregulation of MHC-II and costimulatory molecules is inhibited and consequently there is no lymphoproliferation. IL-10 was shown to play a crucial role in this phenomenon since the inhibitory effect was not observed in IL-10 deficient mice, suggesting that helminth components are able to affect the inductive phase of the immune response, probably through the generation of IL-10, compromising antigen presentation and $\mathrm{T}$ cell proliferation $[40,59]$. Since this effect was shown in inguinal and peritoneal CD $11 c^{+}$ DCs of subcutaneously immunized mice, which might not be reflecting an actual infection in the intestine, it is necessary to study the role of IL-10 production by intestinal DCs in response to A. suum infection. Necator americanus-infected individuals also show significantly downregulated expression of CD86, CD1a, HLA-ABC, and HLA-DR, which reflects an immature phenotype that results in diminished ability to induce T cell proliferation [44]. Lack of DC maturation by E/S form $H$. polygyrus has also been reported. These DCs are able to induce the generation of $\mathrm{CD} 4{ }^{+} \mathrm{CD} 25^{+}$ IL-10-producing $\mathrm{T}$ cells in vitro, thus inhibiting $\mathrm{T}$ cell proliferation and IFN- $\gamma$ production. The authors suggest that E/S might suppress both Th1 and Th2 responses via the generation of regulatory $\mathrm{T}$ cells. In many cases helminth DCs are programmed to synthesize IL-10. The induction of $\mathrm{T}$ reg differentiation is an important mechanism by which, intestinal DCs, exposed to helminths, are able to modulate immune responses $[43,60]$. In fact, Foxp $3^{+} \mathrm{T}$ reg cells develop in the intestine driven by the LP DCs [30]. Products of other non intestinal helminths such as soluble egg antigen from Schistosoma mansoni and ES-62, the immunomodulatory filarial glycoprotein, similarly fail to induce DC activation $[61,62]$.

Several studies, where genomic and proteomic approaches were used to analyze Th2 polarizing DCs exposed to helminth parasites, have shown that few genes or proteins are expressed after stimulation [7, 62]. Although the general picture favors the "default hypothesis" with a limited gene expression, there are examples where, depending on the DC subset exposed, either to E/S products or to the parasite, the response varies (Table 2 ).

Interestingly, and in contrast to the effect of $H$. polygyrus, the E/S products mentioned above, which downmodulate maturation of in vitro generated bone marrow DCs, spleen and MLN-derived DCs obtained from $H$. polygyrus-infected mice, were shown to upregulate costimulatory molecules and synthesize IL-10 and IL-4 $[41,42]$. Also, E/S products from $N$. brasiliensis are able to upregulate costimulatory molecules such as CD86, CD40, and OX40L and induce production of IL-6 and IL-10 [45]. These two examples contradict the "default hypothesis" and highlight the necessity of analyzing better these interactions, taking into account the intestinal microenvironment and the different pathways activated by the different DC subsets. Concomitantly, helminth stimuli involved should be considered, since different helminth parasites and their individual products may use different and possibly multiple mechanisms to induce modulation of DC functions.

Indeed, increasing evidence shows that C-type lectins are likely to play a role in conditioning DCs towards Th2 responses leading to the "alternate pathway model" [57]. Scavenger receptors are also pattern recognition receptors involved in pathogen recognition and facilitation of immune responses expressed in macrophages and DCs [63]. Scavenger receptor-A engagement results in inhibition of LPSstimulated production of IL-12 which might contribute to induce a Th2 phenotype by DCs counteracting with the ability to respond to TLR ligands and induce Th1 responses [64]. In accordance, calreticulin from $H$. polygyrus, a secreted protein that has been implicated in the host-parasite interactions, stimulated robust Th2 responses in mice immunized with the protein devoid of extrinsic adjuvant and stimulated IL-4 and Il-10 secretion in T cells from infected animals. Furthermore, $H$. polygyrus calreticulin interacted with, and was internalized by, scavenger receptor type A on DCs [65]. Concerning costimulation, recently, OX40L upregulation by thymic stromal lymphopoietin (TSLP) has been implicated in generation of Th2 responses [66]. As mentioned above, $\mathrm{E} / \mathrm{S}$ products from $N$. brasiliensis upregulate this TNF family receptor. Thus other molecules besides the classical Th1 costimulators might be involved in inducing Th2 phenotypes (Figure 1).

Additional candidates may include inducible $\mathrm{T}$ cell costimulator (ICOS) and its ligand (ICOSL) that is expressed in DCs. ICOS is able to transmit reverse signals through its ligand to DCs, enhancing antigen presentation in vitro, in 


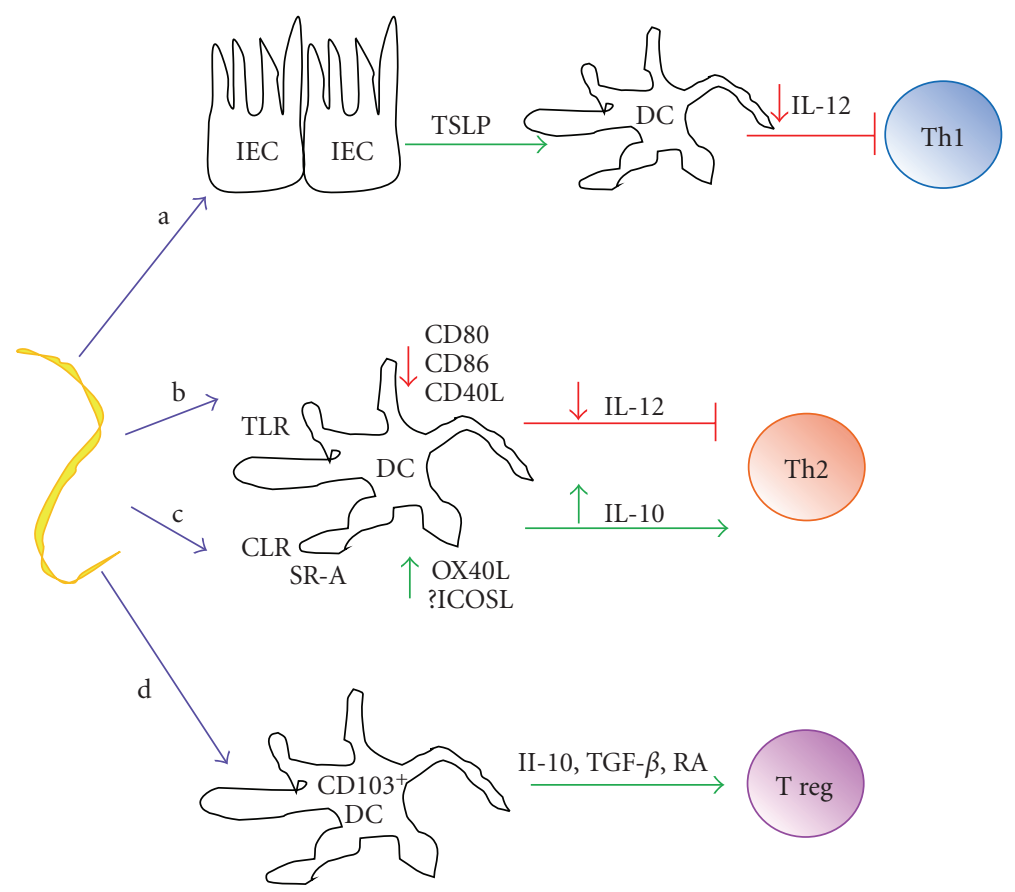

FIGURE 1: Helminth E/S products are able to act on intestinal epithelial cells (IECs) inducing TSLP that engages with the TSLP receptor on DCs and inhibits IL-12/p40. (a) Some E/S products are able to induce signaling through TLRs directly on DCs, resulting in the inhibition of this Th1-promoting cytokine. (b) On the other hand, Th2 responses could be promoted through interactions of helminths with other pattern recognition receptors such as C-type lectins (CLR) or scavenger receptor-A (SR-A) and induction of costimulators such as OX-40L that result in Th2 promotion. (c) Finally, interaction with $\mathrm{CD}_{103^{+}}$DCs may result in the induction of T regs through TGF- $\beta$ and retinoic acid (RA) production. (d) The question of whether different subsets are responsible for these phenomena remains to be determined.

addition to its role in expanding Th2 responses and antibody production [67]. Both ICOSL and ICOS deficient mice have been shown to be defective in early T cell IL-4 production [68]. In a recent study the Th2 response and IL-4 production in the draining MLN were studied during infection with H. polygyrus. IL-4 producing cells were present in germinal centers with a typical $\mathrm{T}$ follicular helper cell phenotype expressing high levels of ICOS [69].

\section{7. "Helminth-Educated DCs"}

In addition to the direct effect of intestinal helminths or their products on DCs, "helminth-educated DCs" can influence immune responses, both Th1 and Th2 types. For example, DCs obtained from mice infected with $H$. polygyrus exacerbated the bacterial inflammation and colitis after adoptive transfer to recipient mice infected with Citrobacter rodentium, a murine bacterial pathogen that induces Th1 protective responses. The helminth primed DCs were shown to secrete IL-10 that modulates the bacteriainduced Th1 response reducing IFN- $\gamma$ production by MLN cells and stimulated IL- 4 production by the colonic mucosa, resulting in a Th2-biased response, and thus a more severe bacterial infection due to less inflammatory components [41]. Regarding Th2 responses, adoptively transferred bone marrow-derived DC pulsed with $N$. brasiliensis $\mathrm{E} / \mathrm{S}$ products induced IL-4, IL- 5 and IL-10 by in vitro activated lymph node cells [45].

\section{Other Cells Affecting DC Function}

Although DCs are capable of directly responding to helminth stimuli, the importance of the interactions of DCs with other cells in the intestinal mucosa and how this cross-talk might influence mucosal immunity require special attention. Intestinal epithelial cells are critical regulators of DCs and of CD4 T cells in the GI tract. Expression of TSLP by epithelial cells limits proinflammatory cytokine production by DCs, inhibiting nonprotective Th1 responses after T. muris infection and promoting the pathogen-specific Th2 responses that result in clearance of infection. Furthermore, TSLP limits expression of IL12/23p 40 and TNF $\alpha$ by DCs and CD4 $4^{+} \mathrm{T}$ cell-derived IFN $\gamma$ and IL-17, and thus prevents intestinal inflammation. TSLP expression was shown to be dependent on the activation of the NF $\kappa$ B pathway in the GI tract [51, 52]. Recently, it has been shown that TSLP does not affect Th2 responses after $H$. polygyrus and $N$. brasiliensis infection. $\mathrm{E} / \mathrm{S}$ products from these two helminths inhibit the CD-40 and LPS-induced production of IL-12p40 by DCs directly, thereby attenuating Th1 responses and enhancing protective Th2 immunity. In contrast, $\mathrm{E} / \mathrm{S}$ products from T. muris are unable to affect DC function; expulsion of this parasite is dependent on TSLP that inhibits IL1-2 p40 during infection [70]. These data demonstrate that different strategies are able to result in attenuation of IL- $12 / \mathrm{p} 40$ production by DCs and concomitant Th2 activation (Figure 1). In another example both differentiated and undifferentiated intestinal 
pig epithelial cells stimulated in vitro with low doses of $T$. suis E/S products predominantly synthesized IL-6 and IL-10. These two cytokines were produced within the first $24 \mathrm{~h}$ of stimulation, suggesting that they might be part of the in vivo primary immune response to this helminth [71]. In addition, mucosal epithelial cells are involved in the recruitment of DCs through the secretion of specific chemokines such as CCL5 and CCL20 [55].

\section{Concluding Remarks}

Intestinal DCs are sui-generis cells as indicated by the different subpopulations, degrees of maturation, specific characteristics, and properties, such as being periscopes of the intestinal lumen. Moreover, survival of intestinal helminths is associated with local DCs which usually generate an antiinflammatory milieu. Despite the increasing number of studies analyzing the effects of helminth products on in vitro generated DCs, very few studies have been designed to try to understand the interaction of intestinal DC subsets with helminths. The importance of this kind of studies is highlighted by the fact that the biological function of each subset of DCs present in the gut is well adapted to its microenvironment and that these cells show different properties compared to DCs in other locations. The mechanism by which DCs induce Th2 responses is still not completely understood. The influence of the regulatory milieu in the intestine should not be disregarded since different signals that act upon DCs might influence the outcome, both locally and systemically. Helminths might prove useful tools as models to understand the mechanisms that are turned on during type 2 responses and might help in developing new strategies to manipulate hazardous immune responses that arise during inflammatory, allergic, or hypersensitivity reactions and probably to diminish the risk for cancer. DCs are known to respond not only to PAMPs, but also to different bioactive metabolites and factors secreted by other cells in their vicinity. The combination of these stimuli might result in the different activation conditions that have been reported for DCs when stimulated by helminths to generate Th2 responses. Thus, the study of the interaction of parasites and host's DCs should include especially in situ studies of microenvironmental conditions, as well as the intrinsic characteristics of intestinal DCs that differ in some ways from DC from other locations or from in vitro generated DCs.

\section{Acknowledgment}

The authors are thankful Dr. Leopoldo Flores-Romo for his critical review of the manuscript and helpful discussions.

\section{References}

[1] R. M. Steinman and Z. A. Cohn, "Identification of a novel cell type in peripheral lymphoid organs of mice. I. Morphology, quantitation, tissue distribution," Journal of Experimental Medicine, vol. 137, no. 5, pp. 1142-1162, 1973.
[2] A. Iwasaki, "Mucosal dendritic cells," Annual Review of Immunology, vol. 25, pp. 381-418, 2007.

[3] J. L. Coombes and F. Powrie, "Dendritic cells in intestinal immune regulation," Nature Reviews Immunology, vol. 8, no. 6, pp. 435-446, 2008.

[4] P. J. Hotez, P. J. Brindley, J. M. Bethony, C. H. King, E. J. Pearce, and J. Jacobson, "Helminth infections: the great neglected tropical diseases," Journal of Clinical Investigation, vol. 118, no. 4, pp. 1311-1321, 2008.

[5] R. M. Maizels, "Infections and allergy-helminths, hygiene and host immune regulation," Current Opinion in Immunology, vol. 17, no. 6, pp. 656-661, 2005.

[6] M. J. G. Johnston, J. A. MacDonald, and D. M. McKay, "Parasitic helminths: a pharmacopeia of anti-inflammatory molecules," Parasitology, vol. 136, no. 2, pp. 125-147, 2009.

[7] L. Carvalho, J. Sun, C. Kane, F. Marshall, C. Krawczyk, and E. J. Pearce, "Review series on helminths, immune modulation and the hygiene hypothesis: mechanisms underlying helminth modulation of dendritic cell function," Immunology, vol. 126, no. 1, pp. 28-34, 2009.

[8] A. J. Stagg, A. L. Hart, S. C. Knight, and M. A. Kamm, "The dendritic cell: its role in intestinal inflammation and relationship with gut bacteria," Gut, vol. 52, no. 10, pp. 15221529, 2003.

[9] B. L. Kelsall and M. Rescigno, "Mucosal dendritic cells in immunity and inflammation," Nature Immunology, vol. 5, no. 11, pp. 1091-1095, 2004.

[10] A. Iwasaki and B. L. Kelsall, "Unique functions of CD11b+, CD $8 \alpha+$, and double-negative Peyer's patch dendritic cells," Journal of Immunology, vol. 166, no. 8, pp. 4884-4890, 2001.

[11] Y. Kanamori, K. Ishimaru, M. Nanno, et al., "Identification of novel lymphoid tissues in murine intestinal mucosa where clusters of c-kit+ IL-7R+ Thy1+ lympho-hemopoietic progenitors develop," Journal of Experimental Medicine, vol. 184, no. 4, pp. 1449-1459, 1996.

[12] D. Bouskra, C. Brézillon, M. Bérard, et al., "Lymphoid tissue genesis induced by commensals through NOD1 regulates intestinal homeostasis," Nature, vol. 456, no. 7221, pp. 507510, 2008.

[13] K. Fujihashi, P. B. Boyaka, and J. R. McGGhee, "Host defences at mucosal surfaces," in Clinical Immunology Principles and Practice, R. R. Rich, Ed., pp. 287-303, Mosby, St. Louis, Miss, USA, 2008.

[14] S. I. Hammerschmidt, M. Ahrendt, U. Bode, et al., "Stromal mesenteric lymph node cells are essential for the generation of gut-homing T cells in vivo," Journal of Experimental Medicine, vol. 205, no. 11, pp. 2483-2490, 2008.

[15] G. Gorfu, J. Rivera-Nieves, and K. Ley, "Role of $\beta 7$ integrins in intestinal lymphocyte homing and retention," Current Molecular Medicine, vol. 9, no. 7, pp. 836-850, 2009.

[16] A. Hahn, N. Thiessen, R. Pabst, M. Buettner, and U. Bode, "Mesenteric lymph nodes are not required for an intestinal immunoglobulin A response to oral cholera toxin," Immunology, vol. 129, no. 3, pp. 427-436, 2009.

[17] S. Fagarasan, K. Kinoshita, M. Muramatsu, K. Ikuta, and T. Honjo, "In situ class switching and differentiation to IgAproducing cells in the gut lamina propria," Nature, vol. 413, no. 6856, pp. 639-643, 2001.

[18] H. Kiyono, J. Kunisawa, J. R. McGhee, and J. Mestecky, "The mucosal immune system," in Fundamental Immunology, William E. Paul, 6th edition, 2008.

[19] K. Shortman and Y.-J. Liu, "Mouse and human dendritic cell subtypes," Nature Reviews Immunology, vol. 2, no. 3, pp. 151$161,2002$. 
[20] J. A. Villadangos and P. Schnorrer, "Intrinsic and cooperative antigen-presenting functions of dendritic-cell subsets in vivo," Nature Reviews Immunology, vol. 7, no. 7, pp. 543-555, 2007.

[21] J. A. Villadangos and L. Young, "Antigen-presentation properties of plasmacytoid dendritic cells," Immunity, vol. 29, no. 3, pp. 352-361, 2008.

[22] H. Ueno, E. Klechevsky, R. Morita, et al., "Dendritic cell subsets in health and disease," Immunological Reviews, vol. 219, no. 1, pp. 118-142, 2007.

[23] A. Flores-Langarica, S. Meza-Perez, J. Calderon-Amador, et al., "Network of dendritic cells within the muscular layer of the mouse intestine," Proceedings of the National Academy of Sciences of the United States of America, vol. 102, no. 52, pp. 19039-19044, 2005.

[24] A. Iwasaki and B. L. Kelsall, "Freshly isolated Peyer's patch, but not spleen, dendritic cells produce interleukin 10 and induce the differentiation of T helper type 2 cells," Journal of Experimental Medicine, vol. 190, no. 2, pp. 229-239, 1999.

[25] K. A. Kadaoui and B. Corthésy, "Secretory IgA mediates bacterial translocation to dendritic cells in mouse Peyer's patches with restriction to mucosal compartment," Journal of Immunology, vol. 179, no. 11, pp. 7751-7757, 2007.

[26] F. G. Chirdo, O. R. Millington, H. Beacock-Sharp, and A. M. Mowat, "Immunomodulatory dendritic cells in intestinal lamina propria," European Journal of Immunology, vol. 35, no. 6, pp. 1831-1840, 2005.

[27] S. Uematsu, K. Fujimoto, M. H. Jang, et al., "Regulation of humoral and cellular gut immunity by lamina propria dendritic cells expressing Toll-like receptor 5," Nature Immunology, vol. 9, no. 7, pp. 769-776, 2008.

[28] M. H. Jang, N. Sougawa, T. Tanaka, et al., "CCR7 is critically important for migration of dendritic cells in intestinal lamina propria to mesenteric lymph nodes," Journal of Immunology, vol. 176, no. 2, pp. 803-810, 2006.

[29] J. L. Coombes, K. R. R. Siddiqui, C. V. Arancibia-Cárcamo, et al., "A functionally specialized population of mucosal CD103' DCs induces Foxp $3^{+}$regulatory $\mathrm{T}$ cells via a TGF- $\beta$-and retinoic acid-dependent mechanism," Journal of Experimental Medicine, vol. 204, no. 8, pp. 1757-1764, 2007.

[30] C.-M. Sun, J. A. Hall, R. B. Blank, et al., "Small intestine lamina propria dendritic cells promote de novo generation of Foxp3 T reg cells via retinoic acid," Journal of Experimental Medicine, vol. 204, no. 8, pp. 1775-1785, 2007.

[31] E. Jaensson, H. Uronen-Hansson, O. Pabst, et al., "Small intestinal $\mathrm{CD}_{103}{ }^{+}$dendritic cells display unique functional properties that are conserved between mice and humans," Journal of Experimental Medicine, vol. 205, no. 9, pp. 21392149, 2008.

[32] J. R. Mora, M. Iwata, B. Eksteen, et al., "Generation of guthoming IgA-secreting B cells by intestinal dendritic cells," Science, vol. 314, no. 5802, pp. 1157-1160, 2006.

[33] M. Rescigno, M. Urbano, B. Valzasina, et al., "Dendritic cells express tight junction proteins and penetrate gut epithelial monolayers to sample bacteria," Nature Immunology, vol. 2, no. 4, pp. 361-367, 2001.

[34] J. Bilsborough, T. C. George, A. Norment, and J. L. Viney, "Mucosal CD $8 \alpha+$ DC, with a plasmacytoid phenotype, induce differentiation and support function of $\mathrm{T}$ cells with regulatory properties," Immunology, vol. 108, no. 4, pp. 481-492, 2003.

[35] C. Johansson and B. L. Kelsall, "Phenotype and function of intestinal dendritic cells," Seminars in Immunology, vol. 17, no. 4, pp. 284-294, 2005.

[36] F.-P. Huang, N. Platt, M. Wykes, et al., "A discrete subpopulation of dendritic cells transports apoptotic intestinal epithelial cells to T cell areas of mesenteric lymph nodes," Journal of Experimental Medicine, vol. 191, no. 3, pp. 435-443, 2000.

[37] N. Contractor, J. Louten, L. Kim, C. A. Biron, and B. L. Kelsall, "Cutting edge: Peyer's patch plasmacytoid dendritic cells (pDCs) produce low levels of type I interferons: possible role for IL-10, TGF $\beta$, and prostaglandin $\mathrm{E} 2$ in conditioning a unique mucosal pDC phenotype," Journal of Immunology, vol. 179, no. 5, pp. 2690-2694, 2007.

[38] R. M. Maizels and M. Yazdanbakhsh, "Immune regulation by helminth parasites: cellular and molecular mechanisms," Nature Reviews Immunology, vol. 3, no. 9, pp. 733-744, 2003.

[39] R. M. Maizels, A. Balic, N. Gomez-Escobar, M. Nair, M. D. Taylor, and J. E. Allen, "Helminth parasites-masters of regulation," Immunological Reviews, vol. 201, pp. 89-116, 2004.

[40] S. R. Silva, J. F. Jacysyn, M. S. Macedo, and E. L. FaquinMauro, "Immunosuppressive components of Ascaris suum down-regulate expression of costimulatory molecules and function of antigen-presenting cells via an IL-10-mediated mechanism," European Journal of Immunology, vol. 36, no. 12, pp. 3227-3237, 2006.

[41] C.-C. Chen, S. Louie, B. A. McCormick, W. A. Walker, and H. N. Shi, "Helminth-primed dendritic cells alter the host response to enteric bacterial infection," Journal of Immunology, vol. 176, no. 1, pp. 472-483, 2006.

[42] H. N. Shi, H. Y. Liu, and C. Nagler-Anderson, "Enteric infection acts as an adjuvant for the response to a model food antigen," Journal of Immunology, vol. 165, no. 11, pp. 6174$6182,2000$.

[43] M. Segura, Z. Su, C. Piccirillo, and M. M. Stevenson, "Impairment of dendritic cell function by excretory-secretory products: a potential mechanism for nematode-induced immunosuppression," European Journal of Immunology, vol. 37, no. 7, pp. 1887-1904, 2007.

[44] R. T. Fujiwara, G. G. L. Cançado, P. A. Freitas, et al., "Necator americanus infection: a possible cause of altered dendritic cell differentiation and eosinophil profile in chronically infected individuals," PLoS Neglected Tropical Diseases, vol. 3, no. 3, article e399, 2009.

[45] A. Balic, Y. Harcus, M. J. Holland, and R. M. Maizels, "Selective maturation of dendritic cells by Nippostrongylus brasiliensissecreted proteins drives Th2 immune responses," European Journal of Immunology, vol. 34, no. 11, pp. 3047-3059, 2004.

[46] A. Balic, K. A. Smith, Y. Harcus, and R. M. Maizels, "Dynamics of $\mathrm{CD} 11 \mathrm{c}^{+}$dendritic cell subsets in lymph nodes draining the site of intestinal nematode infection," Immunology Letters, vol. 127, no. 1, pp. 68-75, 2009.

[47] K. Koyama, "Dendritic cell expansion occurs in mesentericlymph nodes of B10.BR mice infected with the murine nematode parasite Trichuris muris," Parasitology Research, vol. 97, no. 3, pp. 186-190, 2005.

[48] K. Koyama, "Erratum: dendritic cell expansion occurs in mesenteric lymph nodes of B10.BR mice infected with the murine nematode parasite Trichuris muris," Parasitology Research, vol. 97, no. 3, p. 258, 2005.

[49] K. Koyama, "Dendritic cells have a crucial role in the production of cytokines in mesenteric lymph nodes of B10.BR mice infected with Trichuris muris," Parasitology Research, vol. 102, no. 3, pp. 349-356, 2008.

[50] R. D'Elia and K. J. Else, “In vitro antigen presenting cellderived IL-10 and IL-6 correlate with Trichuris muris isolatespecific survival," Parasite Immunology, vol. 31, no. 3, pp. 123 $131,2009$. 
[51] C. Zaph, A. E. Troy, B. C. Taylor, et al., "Epithelial-cell-intrinsic IKK- $\beta$ expression regulates intestinal immune homeostasis," Nature, vol. 446, no. 7135, pp. 552-556, 2007.

[52] B. C. Taylor, C. Zaph, A. E. Troy, et al., "TSLP regulates intestinal immunity and inflammation in mouse models of helminth infection and colitis," Journal of Experimental Medicine, vol. 206, no. 3, pp. 655-667, 2009.

[53] H. Helmby, K. Takeda, S. Akira, and R. K. Grencis, "Interleukin (IL)-18 promotes the development of chronic gastrointestinal helminth infection by downregulating IL-13," Journal of Experimental Medicine, vol. 194, no. 3, pp. 355-364, 2001.

[54] W. C. Gause, J. F. Urban Jr., and M. J. Stadecker, "The immune response to parasitic helminths: insights from murine models," Trends in Immunology, vol. 24, no. 5, pp. 269-277, 2003.

[55] S. M. Cruickshank, M. L. Deschoolmeester, M. Svensson, et al., "Rapid dendritic cell mobilization to the large intestinal epithelium is associated with resistance to Trichuris muris infection," Journal of Immunology, vol. 182, no. 5, pp. 30553062, 2009.

[56] L. R. Schopf, K. F. Hoffmann, A. W. Cheever, J. F. Urban Jr., and T. A. Wynn, "IL-10 is critical for host resistance and survival during gastrointestinal helminth infection," Journal of Immunology, vol. 168, no. 5, pp. 2383-2392, 2002.

[57] A. S. MacDonald and R. M. Maizels, "Alarming dendritic cells for Th2 induction," Journal of Experimental Medicine, vol. 205, no. 1, pp. 13-17, 2008.

[58] D. Jankovic, S. Steinfelder, M. C. Kullberg, and A. Sher, "Mechanisms underlying helminth-induced Th2 polarization: default, negative or positive pathways?" Chemical Immunology and Allergy, vol. 90, pp. 65-81, 2006.

[59] G. Grutz, "New insights into the molecular mechanism of interleukin-10-mediated immunosuppression," Journal of Leukocyte Biology, vol. 77, no. 1, pp. 3-15, 2005.

[60] H. H. Smits, E. C. de Jong, E. A. Wierenga, and M. L. Kapsenberg, "Different faces of regulatory DCs in homeostasis and immunity," Trends in Immunology, vol. 26, no. 3, pp. 123129, 2005.

[61] M. Whelan, M. M. Harnett, K. M. Houston, V. Patel, W. Harnett, and K. P. Rigley, "A filarial nematode-secreted product signals dendritic cells to acquire a phenotype that drives development of Th2 cells," Journal of Immunology, vol. 164, no. 12, pp. 6453-6460, 2000.

[62] S. Ferret-Bernard, R. S. Curwen, and A. P. Mountford, "Proteomic profiling reveals that Th2-inducing dendritic cells stimulated with helminth antigens have a 'limited maturation' phenotype," Proteomics, vol. 8, no. 5, pp. 980-993, 2008.

[63] F. Granucci, C. Vizzardelli, E. Virzi, M. Rescigno, and P. Ricciardi-Castagnoli, "Transcriptional reprogramming of dendritic cells by differentiation stimuli," European Journal of Immunology, vol. 31, no. 9, pp. 2539-2546, 2001.

[64] S. Józefowski, M. Arredouani, T. Sulahian, and L. Kobzik, "Disparate regulation and function of the class A scavenger receptors SR-AI/II and MARCO," Journal of Immunology, vol. 175, no. 12, pp. 8032-8041, 2005.

[65] J. Rzepecka, S. Rausch, C. Klotz, et al., "Calreticulin from the intestinal nematode Heligmosomoides polygyrus is a Th2skewing protein and interacts with murine scavenger receptorA," Molecular Immunology, vol. 46, no. 6, pp. 1109-1119, 2009.

[66] T. Ito, Y.-H. Wang, O. Duramad, et al., "TSLP-activated dendritic cells induce an inflammatory $\mathrm{T}$ helper type 2 cell response through OX40 ligand," Journal of Experimental Medicine, vol. 202, no. 9, pp. 1213-1223, 2005.
[67] G. Tang, Q. Qin, P. Zhang, et al., "Reverse signaling using an inducible costimulator to enhance immunogenic function of dendritic cells," Cellular and Molecular Life Sciences, vol. 66, no. 18, pp. 3067-3080, 2009.

[68] R. I. Nurieva, J. Duong, H. Kishikawa, et al., "Transcriptional regulation of Th2 differentiation by inducible costimulator," Immunity, vol. 18, no. 6, pp. 801-811, 2003.

[69] I. L. King and M. Mohrs, "IL-4-producing CD4 ${ }^{+}$T cells in reactive lymph nodes during helminth infection are $\mathrm{T}$ follicular helper cells," Journal of Experimental Medicine, vol. 206, no. 5, pp. 1001-1007, 2009.

[70] J. C. Massacand, R. C. Stettler, R. Meier, et al., "Helminth products bypass the need for TSLP in Th2 immune responses by directly modulating dendritic cell function," Proceedings of the National Academy of Sciences of the United States of America, vol. 106, no. 33, pp. 13968-13973, 2009.

[71] G. Parthasarathy and L. S. Mansfield, "Trichuris suis excretory secretory products (ESP) elicit interleukin-6 (IL-6) and IL-10 secretion from intestinal epithelial cells (IPEC-1)," Veterinary Parasitology, vol. 131, no. 3-4, pp. 317-324, 2005. 

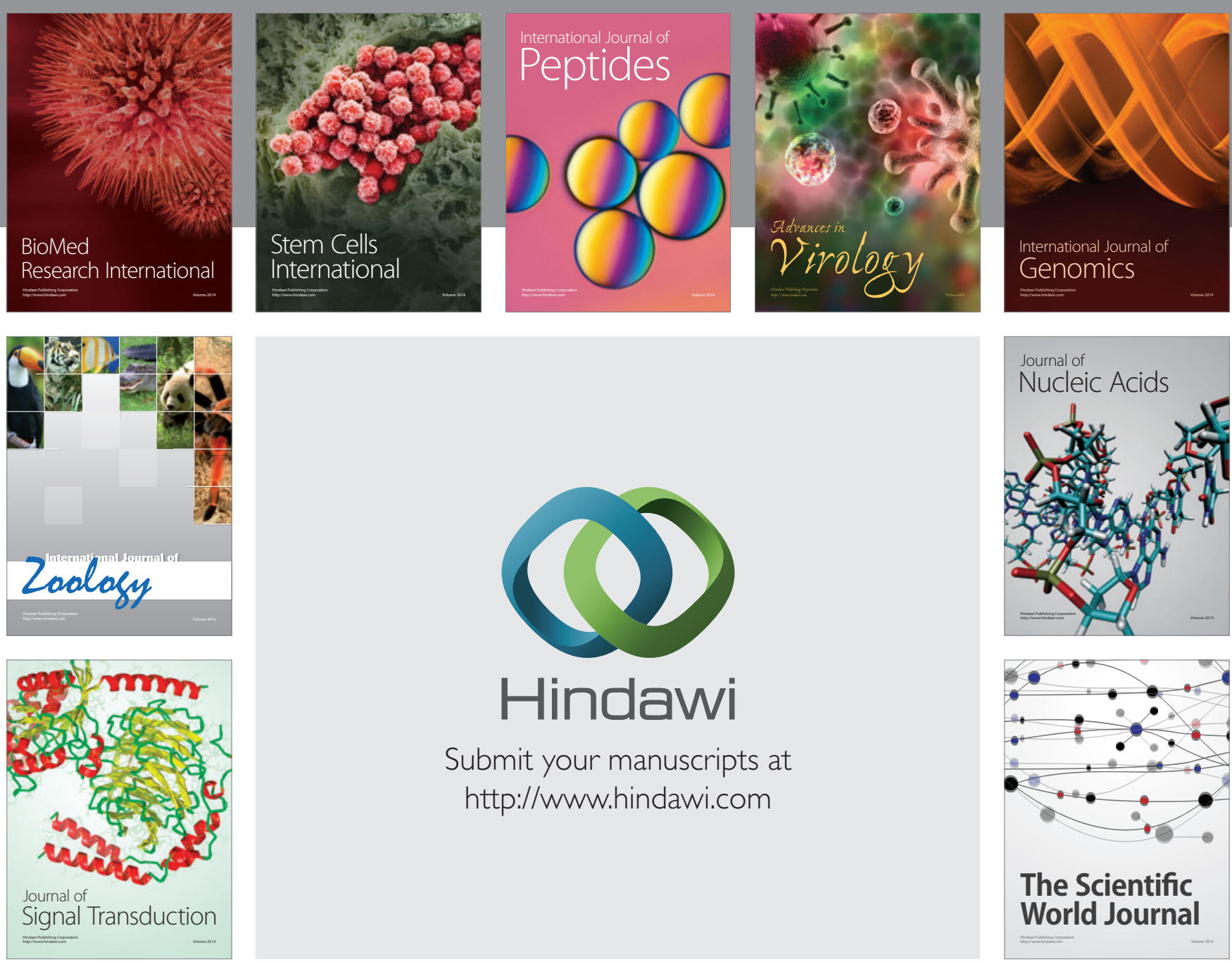

Submit your manuscripts at

http://www.hindawi.com
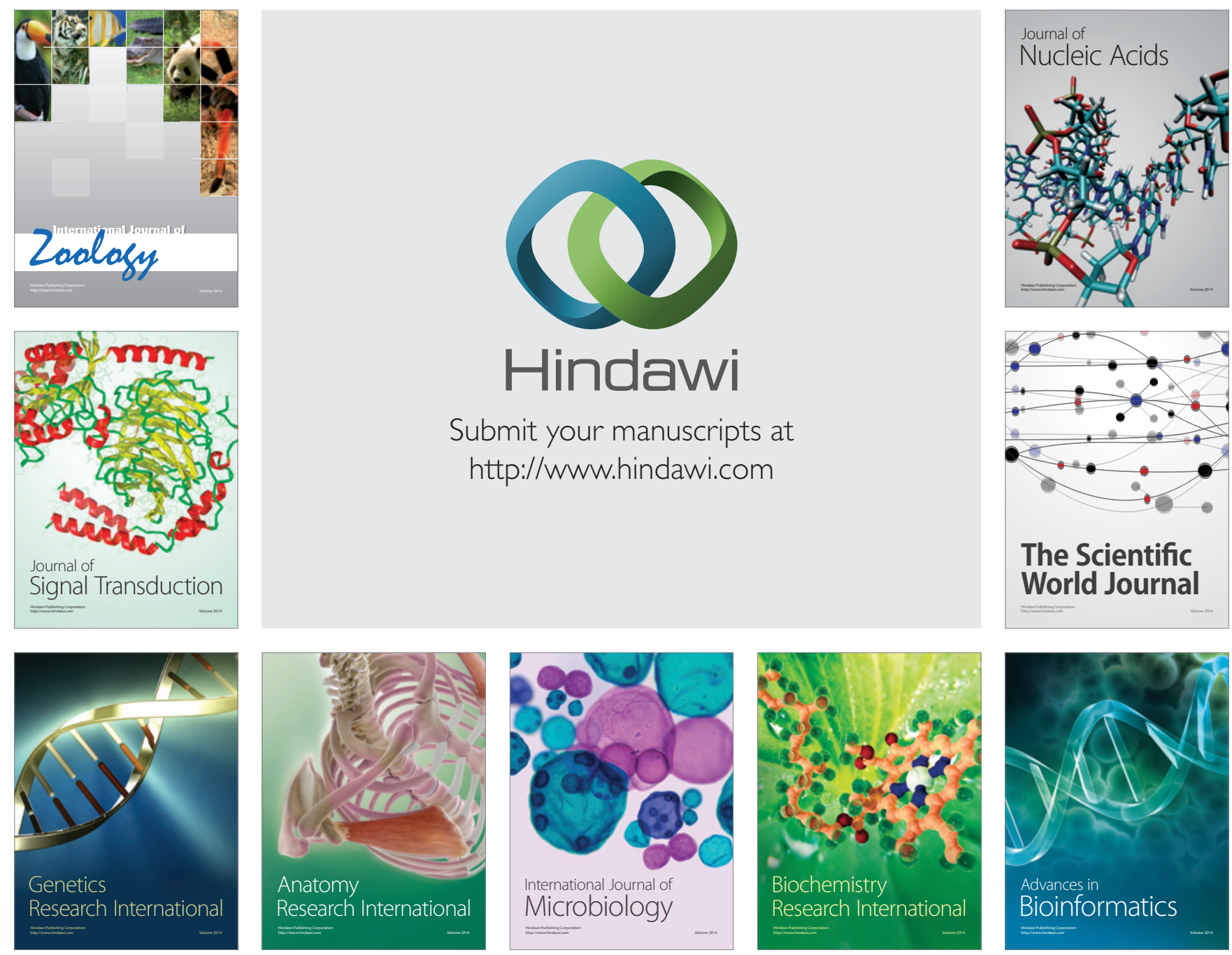

The Scientific World Journal
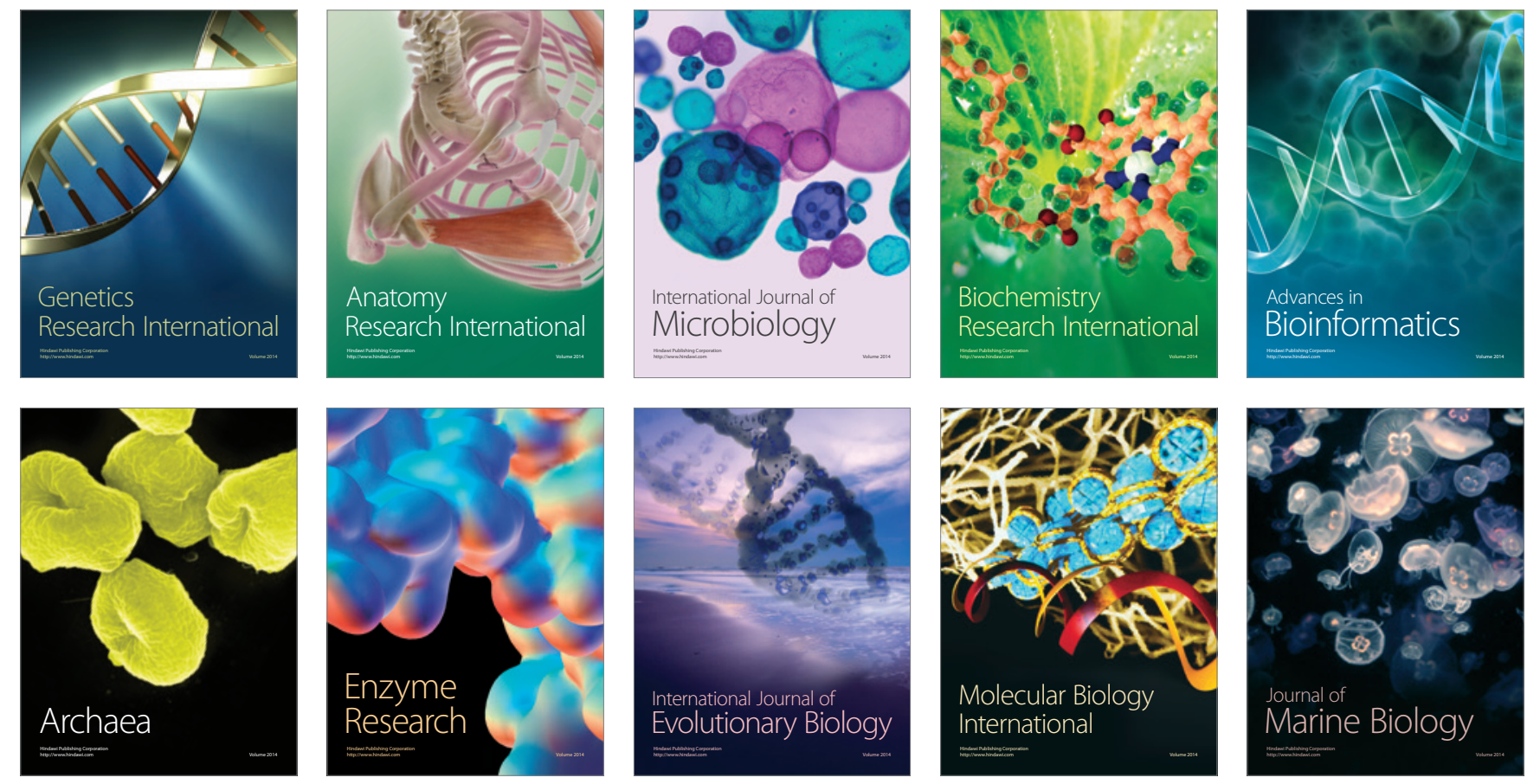